Article

\title{
Extended Spectrum Beta-Lactamase-Resistant Determinants among Carbapenem-Resistant Enterobacteriaceae from Beef Cattle in the North West Province, South Africa: A Critical Assessment of Their Possible Public Health Implications
}

\author{
Lungisile Tshitshi ${ }^{1,2}{ }^{\oplus}$, Madira Coutlyne Manganyi ${ }^{3}$, Peter Kotsoana Montso ${ }^{4}{ }^{\circ}$, \\ Moses Mbewe ${ }^{2}$ and Collins Njie Ateba ${ }^{1,4, *(D)}$ \\ 1 Antimicrobial Resistance and Phage Biocontrol Research Group, Department of Microbiology, School of \\ Biological Sciences, Faculty of Natural and Agricultural Sciences, North West University, Private Bag X2046, \\ Mmabatho 2735, South Africa; Lungisile.Tshitshi@ump.ac.za \\ 2 Faculty of Agriculture and Natural Sciences, University of Mpumalanga, Private Bag X11283, \\ Mbombela 1200, South Africa; Moses.Mbewe@ump.ac.za \\ 3 Unit for Environmental Sciences and Management, North-West University, \\ Potchefstroom 2520, South Africa; madira.manganyi@nwu.ac.za \\ 4 Food Security and Safety Niche Area, Faculty of Natural and Agricultural Sciences, North West University, \\ Private Bag X2046, Mmabatho 2735, South Africa; montsokp@gmail.com \\ * Correspondence: collins.ateba@nwu.ac.za
}

Received: 23 October 2020; Accepted: 12 November 2020; Published: 17 November 2020

check for updates

\begin{abstract}
Carbapenems are considered to be the last resort antibiotics for the treatment of infections caused by extended-spectrum beta-lactamase (ESBL)-producing strains. The purpose of this study was to assess antimicrobial resistance profile of Carbapenem-resistant Enterobacteriaceae (CRE) isolated from cattle faeces and determine the presence of carbapenemase and ESBL encoding genes. A total of 233 faecal samples were collected from cattle and analysed for the presence of CRE. The CRE isolates revealed resistance phenotypes against imipenem (42\%), ertapenem (35\%), doripenem (30\%), meropenem (28\%), cefotaxime, $(59.6 \%)$ aztreonam $(54.3 \%)$ and cefuroxime $(47.7 \%)$. Multidrug resistance phenotypes ranged from 1.4 to $27 \%$ while multi antibiotic resistance (MAR) index value ranged from 0.23 to 0.69 , with an average of 0.40 . Escherichia coli (E. coli), Klebsiella pneumoniae (K. pneumoniae), Proteus mirabilis (P. mirabilis) and Salmonella (34.4, 43.7, 1.3 and 4.6\%, respectively) were the most frequented detected species through genus specific PCR analysis. Detection of genes encoding carbapenemase ranged from $3.3 \%$ to $35 \%$ (blaKPC, blaNDM, blaGES, blaOXA-48, blaVIM and blaOXA-23). Furthermore, CRE isolates harboured ESBL genes (blaSHV (33.1\%), blaTEM (22.5\%), blaCTX-M (20.5\%) and blaOXA (11.3\%)). In conclusion, these findings indicate that cattle harbour CRE carrying ESBL determinants and thus, proper hygiene measures must be enforced to mitigate the spread of CRE strains to food products.
\end{abstract}

Keywords: Enterobacteriaceae; multidrug resistance; carbapenemase; ESBL; resistance genes; cattle

\section{Introduction}

Carbapenem-resistant Enterobacteriaceae (CRE) strains pose a serious threat, especially in public health worldwide [1,2]. These strains cause severe infections such as bloodstream, pneumonia and complicated urinary tract infections in debilitated immunocompromised patients, thus leading to prolonged hospital stay as well as increased healthcare costs and mortality rates [2,3]. According 
to the Centers for Disease Control and Prevention (CDC), direct healthcare costs associated with antimicrobial resistance infections are estimated at $\$ 20$ billion per annum in developed countries [4]. Carbapenem-resistant Enterobacteriaceae strains have been commonly reported in hospital settings and patients in intensive care units [1,5,6]. Although Escherichia coli (E. coli) and Klebsiella pnuemoniae (K. pneumoniae) are the most frequently detected CRE species, other clinical pathogens such Citrobacter freundii, Enterobacter aerogenes (E. aerogenes), Enterobacter cloacae (E. cloacae), P. mirabillis, Salmonella and Serratia marcescens species have been detected from environmental samples [7,8]. In addition, several studies have reported that these species harbours clinically important carbapenemase encoding genes such as blaKPC, blaVIM, blaIMP, blaNDM and blaOXA-48 [9]. These genes are usually plasmid-borne, thereby accelerating horizontal transfer of resistance determinants between the same and/or different species [10]. Worrisome is the fact that Carbapenem-resistant strains may carry extended-spectrum beta-lactamase (ESBL) resistance genes.

Several studies have detected major ESBL genes (blaTEM, blaSHV, blaCTX-M and blaOXA) in CRE strains [11]. Given the fact that carbapenem antibiotics are considered as the last resort for treating infections caused by ESBL-producing strains, presence of carbapenemase and ESBL genes in CRE strains coupled with lack new therapeutic option is cause for concern [9,10]. Against this background, the World Health Organisation (WHO) has classified CRE strains (Acinetobacter baumannii (A. baumannii), E. coli, K. pneumoniae, Pseudomonas aeruginosa (P. aeruginosa) and Enterobacter species) as "critical priority pathogens", which require urgent research and development novel and effective antibiotics [12]. Furthermore, the WHO has published an "action plan", which encourages all countries to establish their own action plan to curb antibiotic resistance phenomenon [13]. This could be achieved via extensive research as well as surveillance and epidemiological studies both nationally and internationally. Data obtained from such studies may assist to strengthen the existing departmental and national policies to mitigate the spread of antimicrobial resistance pathogens.

Despite the fact that most of the studies conducted on CRE have been confined within hospital environment and admitted patients $[5,6,14]$, there is a new evidence indicating that food producing animals, especially cattle, pigs and poultry, may harbour CRE carrying ESBL genes [15-18]. Nevertheless, the number of studies investigating cattle as potential reservoir of CRE harbouring ESBL genes is limited. Hence, the current study was undertaken to determine the occurrence of CRE carrying ESBL determinants in cattle.

\section{Results}

\subsection{Enterobacteriaceae Isolated from Cattle Faeces}

Out of the 233 faecal samples collected from four farms, a total of 280 presumptive isolates belonging to the Enterobacteriaceae family were obtained. Enterobacteriaceae isolates were mostly obtained from Farm_R-B and Farm_N-D (101 and 92, respectively). Only 59 and 28 of the isolates were obtained from Farm_K-A and Farm_L-C, respectively.

\subsection{Carbapenem Resistance Isolates}

All 280 isolates revealed various antimicrobial susceptibility profiles against four carbapenem antimicrobial agents tested; Figure 1. Of these, 69.3\% of the isolates showed intermediate or resistance to one or more of the four carbapenem antibiotics. The isolates revealed resistance to imipenem (42\%), ertapenem (35\%), doripenem (30\%) and meropenem (28\%), while intermediate resistance was shown by 26, 31, 33 and 41\%, respectively. All 194 isolates that exhibited carbapenem resistance phenotypes were positive for the modified Hodge test. A total of 151 isolates were capable of growing on Brilliance ${ }^{\mathrm{TM}}$ ESBL agar and produced colonies with different colours (pink, green, colourless and brown halo), indicating that the isolates could be composed of different species such as E. coli, Klebsiella, Enterobacter, Serratia, Citrobacter and Salmonella, Proteus. 


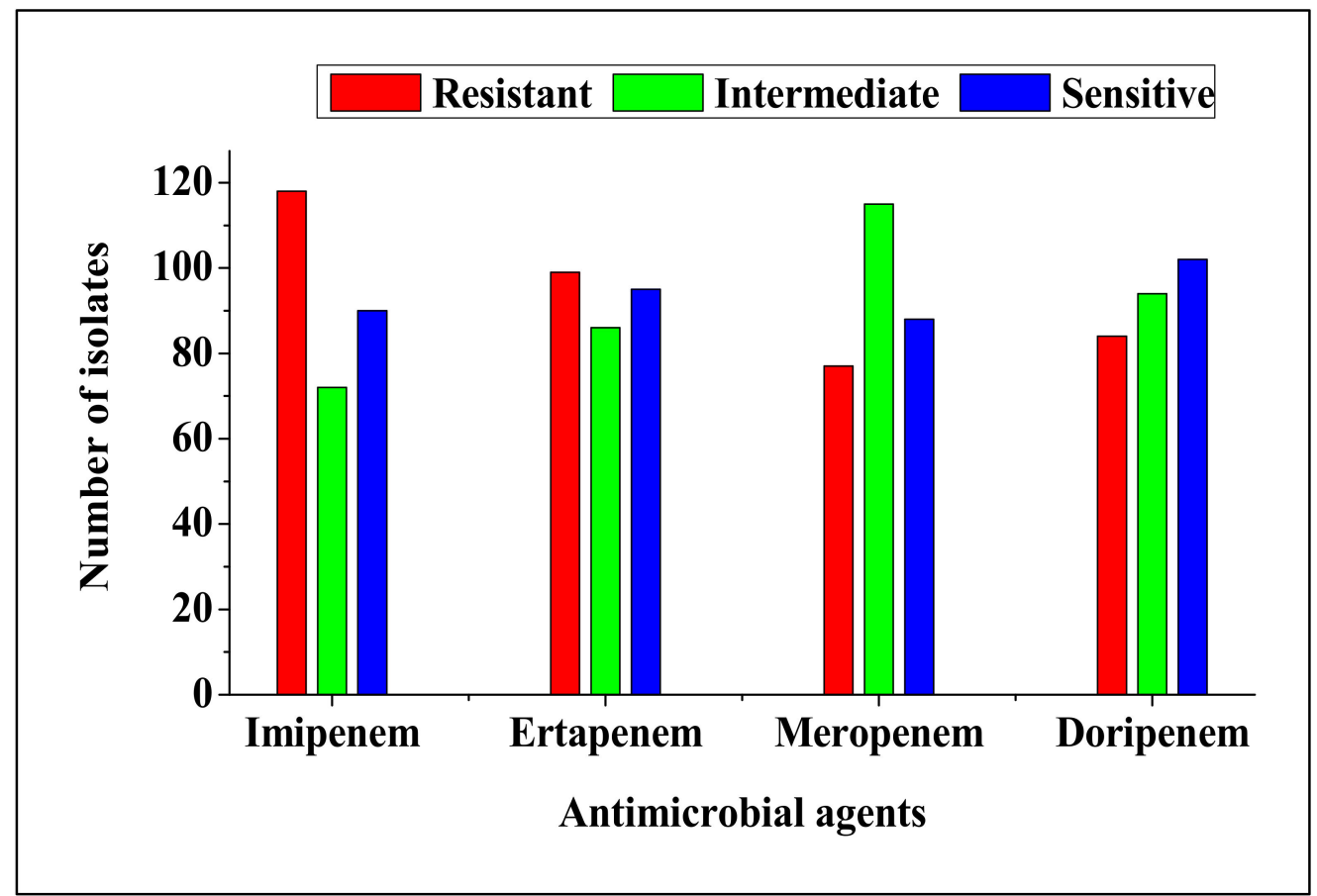

Figure 1. Antimicrobial susceptibility profile of Enterobacteriaceae isolated from cattle faeces.

\subsection{Antimicrobial Resistance Profile of CRE}

The 151 isolates that were Carbapenem-resistant and also positive for ESBL production revealed various antimicrobial resistance profiles against 13 different antibiotics tested, Figure 2 . The isolates were resistant to at least two or more antimicrobial agents tested. Most of the isolates were resistant to cefotaxime, aztreonam and cefuroxime (59.6, 54.3 and 47.7\%, respectively). Resistance to other antimicrobial agents (ceftiofur, amoxicillin, piperacillin, ticarcillin, cephalothin, ceftazidime and cefoxitin) ranged from 39.1 to $43.7 \%$. Low resistance (12.6 and 9.3\%) was observed for ciprofloxacin and amoxicillin-clavulanate, respectively. Large proportion (93.4\%) of CRE isolates were resistant to three or more antimicrobial agents and were defined as multidrug resistant strains. Multidrug resistance phenotypes ranged from 1.4 to $27 \%$, with the most common MDR pattern being observed against four, five and six different antimicrobial agents (27, 27 and 22\%, respectively); Figure 3. Multi antibiotic resistance (MAR) index value ranged from 0.23 to 0.69 , with an average of 0.40 . The MAR indices 0.31 , 0.38 and 0.46 were the most frequently observed among CRE isolates, Figure 4 and Table S1. 


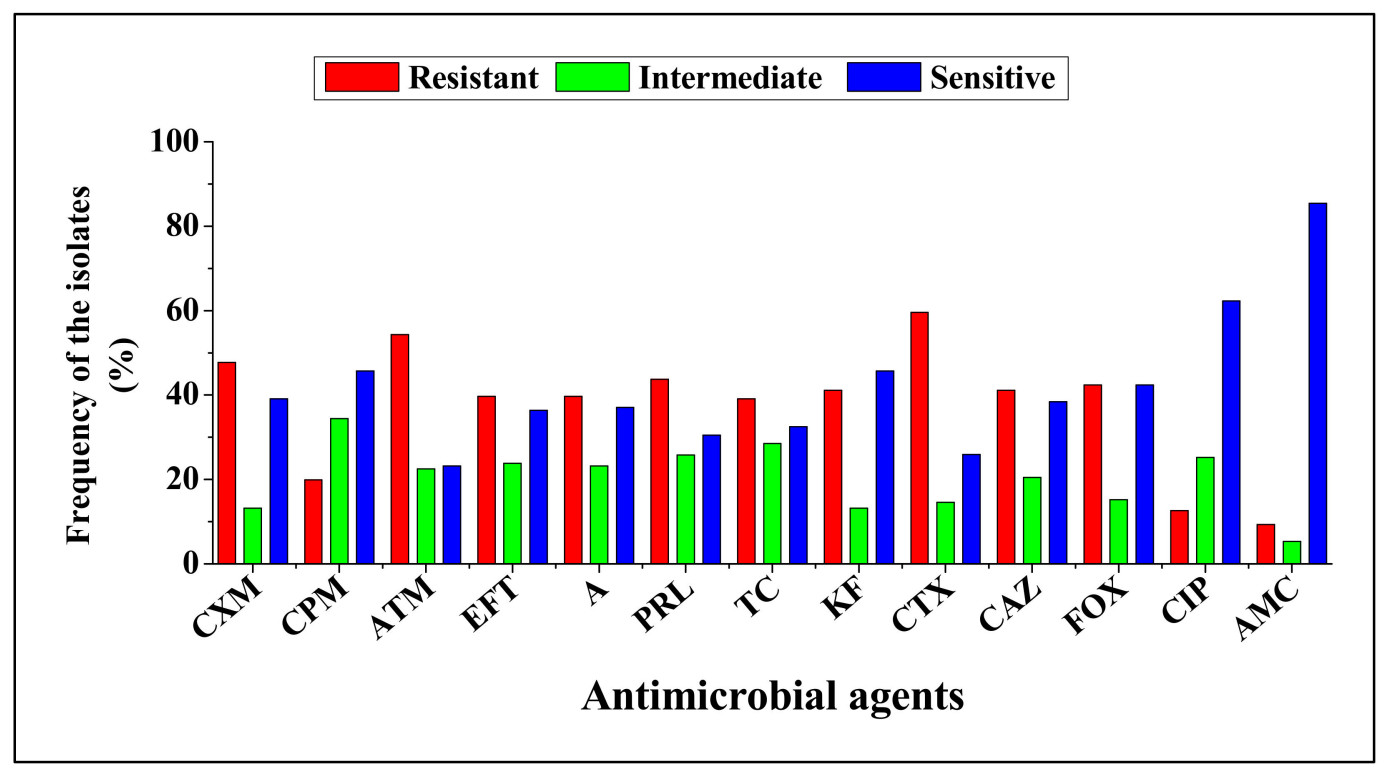

Figure 2. Antimicrobial susceptibility pattern of carbapenem-resistant Enterobacteriaceae. $\mathrm{A}=$ Amoxicillin, $\mathrm{AMC}=$ Amoxicillin-clavulanate, $\mathrm{ATM}=$ Aztreonam, $\mathrm{CPM}=$ Cefepime, CTX = Cefotaxime, FOX = Cefoxitin, CAZ = Ceftazidime, CXM = Cefuroxime, EFT = Ceftiofur, $\mathrm{KF}=$ Cephalothin, $\mathrm{CIP}=$ Ciprofloxacin, $\mathrm{PRL}=$ Piperacillin and $\mathrm{TC}=$ Ticarcillin.

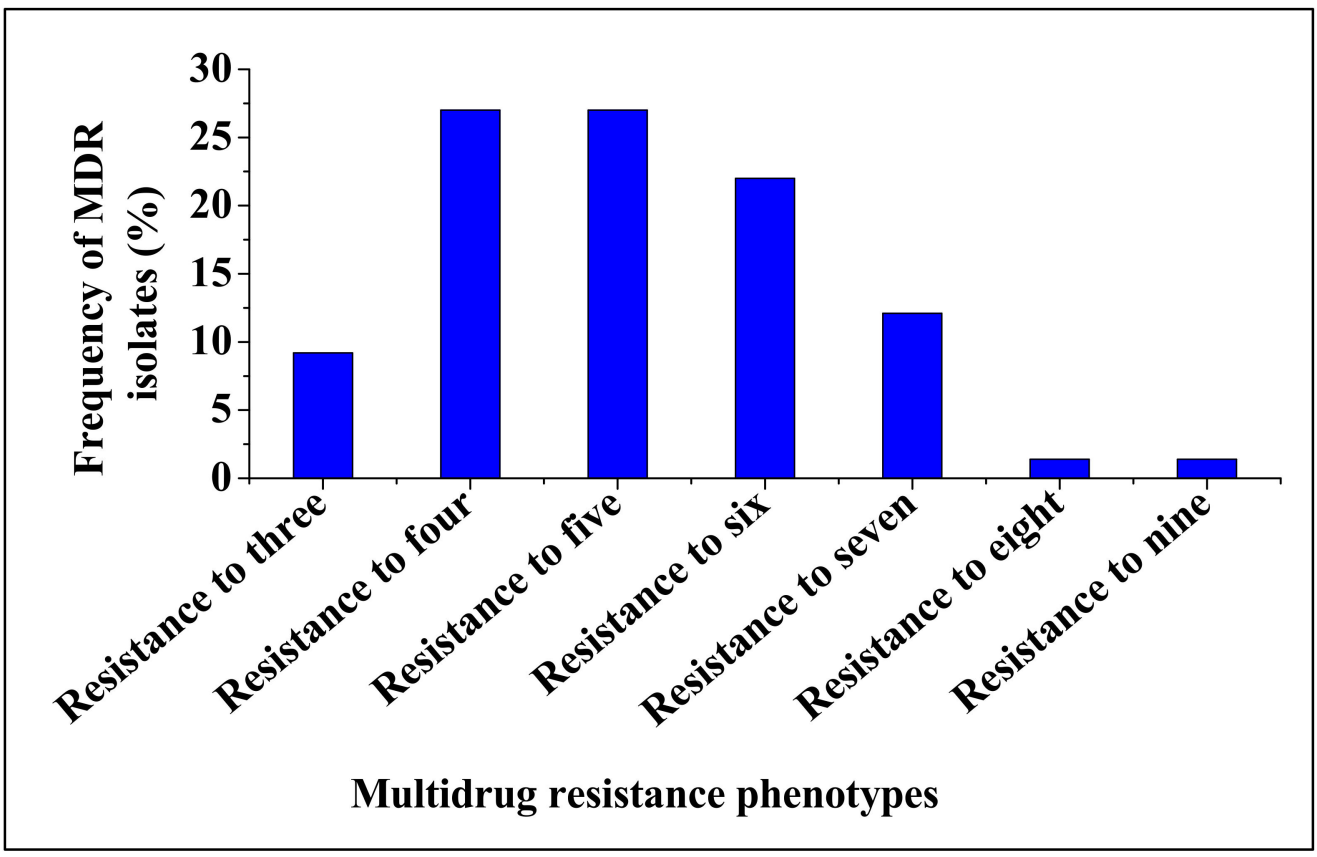

Figure 3. Frequency of multidrug resistance pattern in CRE isolated from cattle faeces. 


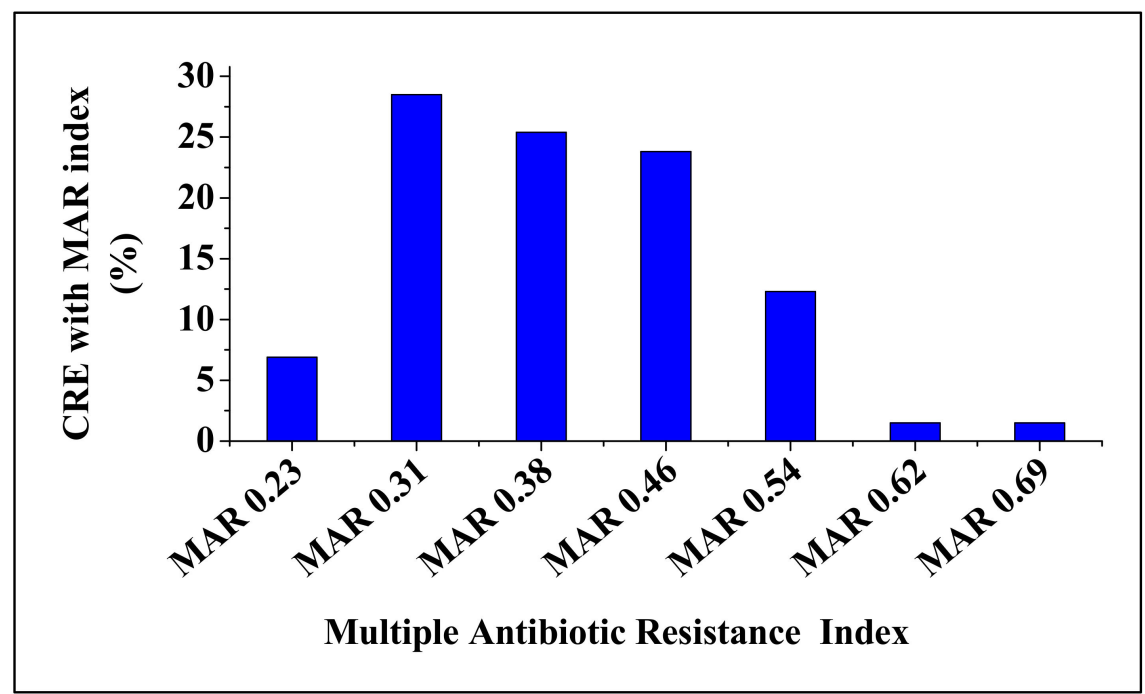

Figure 4. Mean frequency of multiple antibiotic resistance profiles of CRE strains.

\subsection{Molecular Identification of CRE Species}

A total of 151 CRE isolates were confirmed through amplifying the 16S rRNA conserved region. Of these, $84 \%$ were confirmed at species level (E. coli $(34.4 \%)$, K. pneumoniae $(43.7 \%)$, P. mirabilis $(1.3 \%)$ and Salmonella (4.6\%)) through genus-specific PCR analysis. The remaining $16 \%$ of the isolates that could not be identified as either one of these four species were classified as unspecified CRE species.

\subsection{Detection of Genes Encoding Carbapenemases in CRE}

All six carbapenemase-encoding genes screened were detected in CRE isolated from cattle faeces. The blaKPC (35.8\%), blaNDM (20.5\%) and blaGES (17.9\%) were the most frequently detected genes, Figure 5. The blaOXA-48, blaVIM and blaOXA-23 were detected in low proportions $(10.6,6.6$ and $3.3 \%$, respectively). Simultaneous detection of blaKPC_blaOXA-23 (2.6\%) blaKPC_blaNDM (1.3\%) and blaGES_blaOXA-48 (1.3\%) genes in some of the isolates were observed. In general, large proportion $(94.7 \%)$ of CRE species carried carbapenem resistance genes. Carbapenemase encoding genes were commonly detected in E. coli and K. pneumoniae species (96.2 and $92.4 \%$, respectively), while all Salmonella and Proteus mirabilis species detected in this study possessed CR determinants; Table 1.

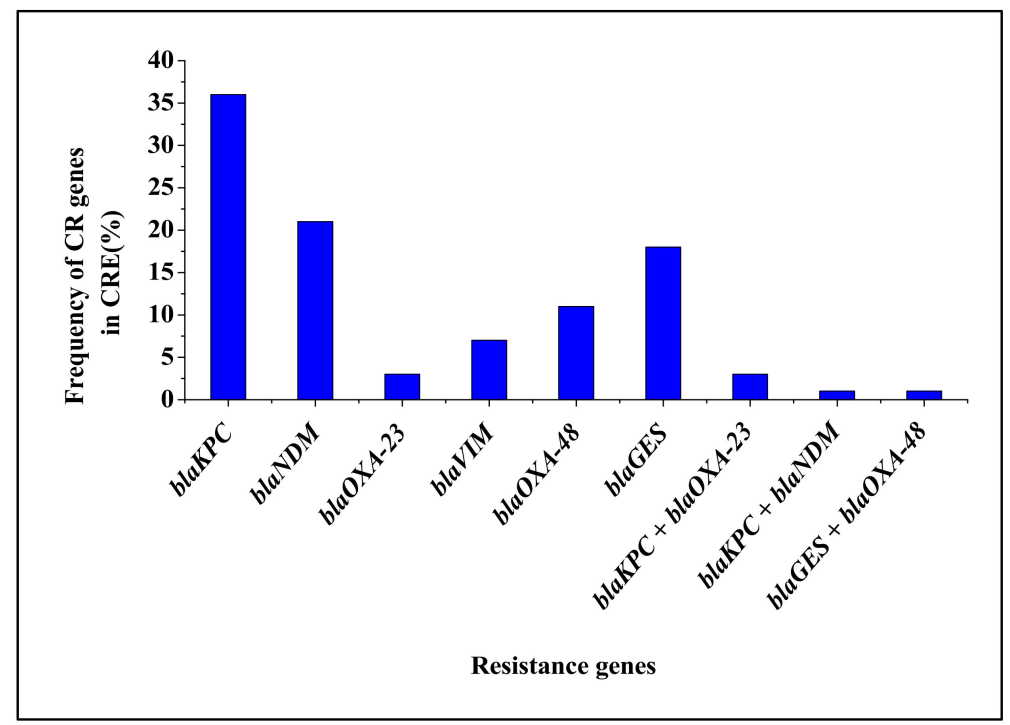

Figure 5. Number of carbapenemase-encoding genes detected in CRE isolated from cattle faeces. 
Table 1. Proportion of CRE species harbouring carbapenemase genes.

\begin{tabular}{|c|c|c|c|c|c|c|c|c|c|c|}
\hline \multirow{2}{*}{ CRE Species } & \multirow{2}{*}{ No. of Isolates } & \multicolumn{9}{|c|}{ Carbapenemase Encoding Genes (\%) } \\
\hline & & $b l a_{K P C}$ & $b l a_{N D M}$ & bla $a_{O X A-23}$ & $b^{\prime} a_{V I M}$ & bla ${ }_{O X A-48}$ & $b l a_{G E S}$ & bla $_{K P C}{ }_{-} b l a_{O X A-23}$ & $b l a_{K P C}{ }_{-} b l a_{N D M}$ & bla $a_{G E S \_} b l a_{O X A-48}$ \\
\hline E. coli & 52 & 34.6 & 32.7 & 3.8 & 1.9 & 13.5 & 9.6 & 0.0 & 3.8 & 0.0 \\
\hline K. pneumoniae & 66 & 42.4 & 12.1 & 1.5 & 3.0 & 6.1 & 27.3 & 6.1 & 0.0 & 1.5 \\
\hline P. mirabilis & 2 & 0.0 & 0.0 & 50.0 & 0.0 & 50.0 & 0.0 & 0.0 & 0.0 & 0.0 \\
\hline Salmonella species & 7 & 28.6 & 42.9 & 14.3 & 0.0 & 14.3 & 0.0 & 0.0 & 0.0 & 0.0 \\
\hline $\begin{array}{l}\text { Unspecified CRE } \\
\text { species }\end{array}$ & 24 & 25.0 & 12.5 & 0.0 & 29.2 & 12.5 & 16.7 & 0.0 & 0.0 & 4.2 \\
\hline Total & 151 & 35.8 & 20.5 & 3.3 & 6.6 & 10.6 & 17.9 & 2.6 & 1.3 & 1.3 \\
\hline
\end{tabular}


Large proportion (42.4 and 27.3\%) of K. pneumoniae species harboured blaKPC and blaGES, followed by 34.6 and $32.7 \%$ of E. coli species carrying blaKPC and blaNDM, respectively. Salmonella species (42.9 and $28.6 \%$ ) carried blaNDM and blaKPC, while unspecified CRE species (29.2 and 25.0\%) of possessed of blaVIM and blaKPC and 50\% of P. mirabilis species harboured either blaOXA-23 or blaOXA-48. Some of E. coli species (3.8\%) also possessed blaKPC_blaNDM, while K. pneumoniae species (6.1 and 1.5\%) harboured blaKPC_blaOXA-23 and blaGES_blaOXA-48, followed by unspecified CRE species (4.2\%) possessing blaGES_blaOXA-48.

\subsection{Detection of ESBL Determinants in CRE}

All four major ESBL-encoding genes screened were detected in CRE isolates. The blaSHV (33.1\%), blaTEM (22.5\%) and blaCTX-M (20.5\%) were most frequently detected genes while blaOXA $(11.3 \%)$ detection was very low, Figure 6. Concurrent detection by blaOXA_blaCTX-M (7.3\%) and blaSHV_blaTEM (5.3\%) genes in CRE isolates were observed. Generally, 87.4\% CRE species harboured ESBL genes. As indicated in Table 2, most of E. coli (86.5\%) and K. pneumoniae (84.8\%) and Salmonella $(85.7 \%)$ species were positive for ESBL genes. All P. mirabilis and 95.8\% unspecified CRE species carried ESBL genes. Large proportion (45.5\%) of K. pneumoniae species harboured blaSHV. E. coli species (34.6 and 26.9\%) and Salmonella species (57.1 and 28.6\%) carried blaCTX-M and blaTEM, respectively). The $33.3 \%$ of unspecified CRE species harboured blaSHV while $50 \%$ of $P$. mirabilis species carried either blaTEM or blaOXA. Some E. coli (9.6 and 3.8\%) and K. pneumoniae species (3.0 and 12.1\%) possessed blaSHV_blaTEM and blaOXA_blaCTX-M, respectively. Salmonella (14.3\%) and P. mirabilis species (9.1\%) possessed blaOXA_blaCTX-M, while unspecified CRE species (4.2\%) harboured blaSHV_blaTEM.

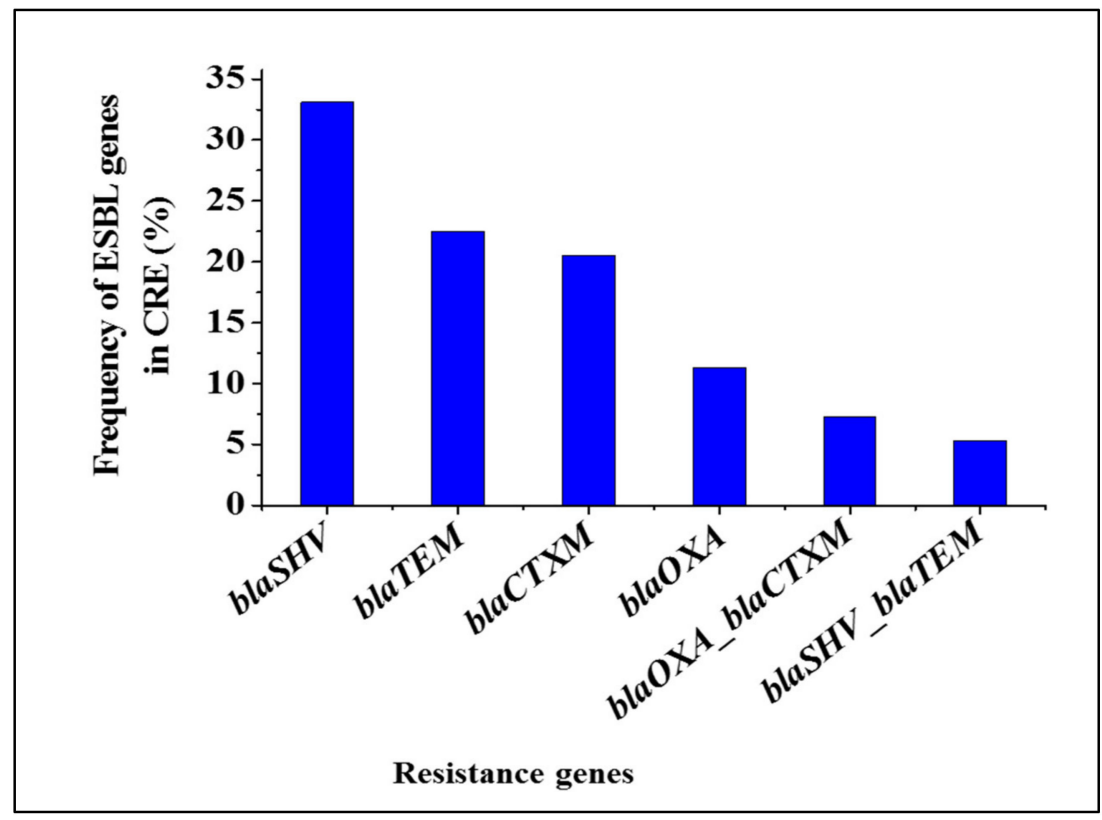

Figure 6. Frequency of ESBL-encoding genes detected in CRE isolated from cattle faeces. 
Table 2. Proportion of CRE species carrying ESBL genes.

\begin{tabular}{|c|c|c|c|c|c|c|c|}
\hline \multirow{2}{*}{ CRE Species } & \multirow{2}{*}{ No. of Isolates } & \multicolumn{6}{|c|}{ ESBL Encoding Genes (\%) } \\
\hline & & $b l a_{S H V}$ & bla $_{T E M}$ & bla $_{C T X-M}$ & $b^{\prime l a X A}$ & bla $_{O X A \_b l a}{ }_{\mathrm{CTX}-\mathrm{M}}$ & $b l a_{S H V \_} b l a_{T E M}$ \\
\hline E. coli & 52 & 23.1 & 26.9 & 34.6 & 1.9 & 3.8 & 9.6 \\
\hline K. pneumoniae & 66 & 45.5 & 16.7 & 9.1 & 13.6 & 12.1 & 3.0 \\
\hline P. mirabilis & 2 & 0.0 & 50.0 & 0.0 & 50.0 & 9.1 & 0.0 \\
\hline Salmonella species & 7 & 0.0 & 28.6 & 57.1 & 0.0 & 14.3 & 0.0 \\
\hline Unspecified CRE species & 24 & 33.3 & 25.0 & 12.5 & 25.0 & 0.0 & 4.2 \\
\hline Total & 151 & 33.1 & 22.5 & 20.5 & 11.3 & 7.3 & 5.3 \\
\hline
\end{tabular}




\section{Discussion}

This study reports the occurrence of Carbapenem-resistant Enterobacteriaceae from cattle faeces obtained from different commercial farms in the North West province, South Africa. Overall, 280 Enterobacteriaceae were successfully isolated. Notably, Enterobacteriaceae isolates revealed intermediate or resistance to carbapenem antibiotics (imipenem, ertapenem, doripenem and meropenem) tested. Moreover, resistance to carbapenem antibiotics ranged from 28 to $42 \%$. High resistance was observed against imipenem (42\%). This finding was lower than $98 \%$ imipenem resistance reported in the previous study [19]. Interestingly, all Enterobacteriaceae isolates that revealed intermediate and/or resistant phenotypes against carbapenem antibiotics tested positive for the modified Hodge test and were thus regarded as CRE strains [15,20]. In addition, the isolates were capable of growing on Brilliance ${ }^{\mathrm{TM}}$ ESBL media, and this suggests that those isolates carry ESBL determinants [15]. Since carbapenem antibiotics are regarded as being the last resort for the treatment of infections caused by ESBL-producing Enterobacteriaceae or multidrug resistant pathogens, resistance to this antibiotic group may exacerbate morbidity and mortality rates in humans [14,21-23]. Therefore, monitoring of CRE and the genes associated with CR in food producing animals is essential to determine prevalence of Carbapenem-resistant pathogens in cattle.

Extensive use of antibiotics in agriculture, especially in food producing exacerbate the emergence antibiotic resistant pathogens in food producing animals. Several studies have reported the occurrence of antimicrobial resistant pathogens in foodborne pathogens [24-26]. In this study, Carbapenem-resistant Enterobacteriaceae isolates revealed various resistance patterns against beta-lactam, 1st, 2nd and 3rd cephalosporins antibiotics. Most of the isolates were highly resistant to cefotaxime, aztreonam and cefuroxime (59.6, 54.3 and 47.7\%, respectively). These results corroborate the previous study [26]. In addition, large proportion (93.4\%) of CRE isolates revealed MDR phenotypes, which is higher than the $83.78 \%$ MRD phenotype previously reported in spinach in South Africa [27]. Moreover, resistance against a maximum of nine antimicrobial agents was observed, suggesting that some of the CRE isolates obtained in this study could possibly be considered as extensively drug resistant (XDR) strains [28]. Interestingly, the MAR index value of 129 MDR strains ranged from 0.23 to 0.69, with an average of 0.40. Although these findings were lower than that of the other study [29], the MAR indices observed in this study were $>0.2$. A MAR index of 0.2 or higher indicates high-risk sources of contamination [30,31]. This implies that continuous monitoring of carbapenem resistance in food producing animals, especially cattle is crucial to ensure the safety of food.

Increasing emergence of Carbapenem-resistant species poses a severe threat in public health [32]. Several studies reported have reported the occurrence of CRE in food, animals, water, hospitalised patients and hospitals and/or clinic environments [2,5,33,34]. E. coli and K. pneumoniae are the most predominant species associated with carbapenem resistance [32]. Overall, four CR species (E. coli, K. pneumoniae, Salmonella and P. mirabilis) were identified using genus-specific PCR analysis in this study. Similar to other studies [5,34,35], K. pneumoniae (43.7\%) and E. coli $(34.4 \%)$ species were the most commonly detected species. Moreover, other CR species, Salmonella (4.6\%) and P. mirabilis (1.3\%) were detected in low quantity. However, $16 \%$ of CRE isolates could not be identified at the specie level and were classified as 'unspecified CRE species'.

Carbapenem resistance determinants (blaKPC, blaNDM, blaOXA-23, blaVIM, blaOXA-48 and blaGES) have been detected in CRE isolated from different sources such as hospitals, drinking and recreational water, agricultural environments, food producing animals and food products [23]. In this study, 97.4\% of CRE isolates possessed carbapenem resistance genes were detected in CRE species. These findings were higher than the $14.3 \%$ detection of carbapenem resistance determinants reported in the previous study in from vegetables [33]. This variation could be attributed to different sample sources and isolation methods used per study. Furthermore, high detection of CR genes in this study indicates that the use of carbapenem antibiotics in agriculture may increase the occurrence of CR pathogens in food producing animal, especially cattle. As a result, this may accelerate dissemination of CR pathogens to humans through consumption of contaminated food [22,33,36]. Based on each 
species, E. coli (96.2\%), K. pneumoniae (92.4\%), Salmonella (100\%), P. mirabilis (100\%) and unspecified CRE species (95.8\%) carried carbapenem resistance determinants. However, these findings were higher than that of the other studies $[14,33,37]$. However, these findings were higher than those of the other studies $[14,33,37]$. A possible explanation for this variation could be attributed to differences in the source of samples and geographical location and management practices per farm, which may have different selective pressure for the antimicrobial resistance levels [31]. Most K. pneumoniae species and E. coli carried blaKPC, while Salmonella species possessed the blaNDM gene. In addition, the P. mirabilis species possessed either blaOXA-23 or blaOXA-48, whereas unspecified CRE species possessed of blaVIM. Some E. coli species possessed a combination of blaKPC_blaNDM, while K. pneumoniae species harboured blaKPC_blaOXA-23 and blaGES_blaOXA-48, followed by unspecified CRE species possessing blaGES_blaOXA-48. Given that E. coli and K. pnuemoniae species cause severe infection in humans, detection of Carbapenem-resistant determinants in these species cannot be overemphasised.

In Enterobacteriaceae, ESBL determinants (blaSHV, blaTEM, blaCTX-M and blaOXA) are considered as the primary mechanism for mediating beta-lactam antibiotics resistance in Enterobacteriaceae [38,39]. Given that extended spectrum cephalosporins antibiotics are used in veterinary medicine, this has resulted in the emergence of ESBL resistance genes in food producing animals, especially cattle [40]. Numerous studies have detected ESBL determinants in Enterobacteriaceae isolated from food, cattle and pigs [26,37,41]. Likewise, ESBL-encoding genes (blaSHV, blaTEM, blaCTX-M and blaOXA) were detected in this study. Overall, large proportion (87.4\%) of CRE isolates harboured ESBL genes. This finding was higher than that of the previous studies, which reported the occurrence of ESBL-producing Enterobacteriaceae in cattle and food [26,42,43]. The blaSHV, blaTEM and blaCTX-M were the most frequently (20.5-33.1\%) detected genes. However, these findings were lower than those of the previous studies, which reported the prevalence of ESBL-producing strains obtained from hospital environment $[27,44,45]$. The variation could be attributed to the source of samples, geographical location and the number of isolates analysed per study. Furthermore, blaOXA was detected at low rate. Based on each species, large proportion (84.8-100\%) of CRE species (E. coli (86.5\%), K. pneumoniae (84.8\%), Salmonella (85.7\%) and P. mirabilis (100\%) unspecified CRE species (95.8\%)) harboured ESBL genes. Large proportions of K. pneumoniae (45.5\%) and unspecified CRE (33.3\%) species harboured blaSHV. This finding is consistent with the other study, in which blaSHV was predominantly detected in K. pnuemoniae [44]. Moreover, E. coli (34.6\%) and Salmonella species (57.1\%) possessed blaCTX-M, while P. mirabilis (50\%) species carried either blaTEM or blaOXA. Notably, some E. coli and K. pneumoniae species harboured blaSHV_blaTEM, which is similar to another study from Eastern Cape Province, South Africa [44]. Another ESBL combination observed was blaOXA_blaCTX-M. These findings suggest that strict measures must be implemented throughout the food chain to mitigate transmission of antimicrobial resistant pathogens to the environment, as well as humans.

\section{Materials and Methods}

\subsection{Ethical Consideration}

Ethical clearance and approval for the study was obtained from the Animal Care Research Ethics Committee (AnimCare REC), of the North-West University, South Africa (Reference number: NWU-00066-15-S9).

\subsection{Study Area, Sample Collection and Processing}

This is a cross-sectional study, and it was conducted from July 2016 to July 1017 in the North-West province, South Africa. A total of 233 faecal samples were collected from four cattle farms (Farm_K-A, Farm_R-B, Farm_L-C and Farm_N-D) located in the Ngaka Modiri Molema district. The selection of the sampling sites was based on the accessibility and the wiliness of the farm owners to participate in the study. The farms had 100 to 400 head of cattle. Sampling was done between July 2016 and August 2017 and all the ethical procedures were followed during handling of the animals. Faecal samples were 
collected directly from the rectum of individual animals using sterile arm-length gloves and in order to avoid duplication of sampling, the cattle were locked into their respective handling pens. Samples were placed in sterile sample collection bottles, labelled appropriately and immediately transported on ice packs to the Antimicrobial Resistance and Phage Biocontrol Research Group (ARPHBRG) laboratory, North-West University for microbial analysis. For bacteria isolation, $1 \mathrm{~g}$ of each sample was dissolved in $2 \%(w / v)$ sterile buffered peptone water (Biolab, Lawrenceville, GA, USA). Aliquot of $5 \mu \mathrm{L}$ of each sample (mixture) was transferred into $10 \mathrm{~mL}$ buffered peptone water. Ten-fold serial dilutions were prepared and aliquots of $100 \mu \mathrm{L}$ from each dilution was spread-plated on MacConkey agar supplemented with crystal violet and salt (Biolab, Lawrenceville, GA, USA) using a standard procedure. The plates were incubated aerobically at $37^{\circ} \mathrm{C}$ for $24 \mathrm{~h}$. The colonies depicting different colours (pale, pink or red) were selected and purified by streaking on MacConkey agar and the plates were at $37^{\circ} \mathrm{C}$ for $24 \mathrm{~h}$. Pure colonies were preserved in $20 \%$ glycerol and the stock cultures were stored at $-80^{\circ} \mathrm{C}$ for future use.

\subsection{Culture-Based Methods for Identification of Carbapenem Resistance Enterobacteriaceae Colonies}

A total of 280 isolates were screened for carbapenem resistance using Kirby-Bauer disc diffusion method [46], the isolates were revived on MacConkey agar and the plates were at $37^{\circ} \mathrm{C}$ for $24 \mathrm{~h}$. After incubation, one colony was transferred into $50 \mathrm{~mL}$ falcon tubes containing $10 \mathrm{~mL}$ nutrient broth. The tubes were incubated at $37^{\circ} \mathrm{C}$ for $20 \mathrm{~h}$. The turbidity of the cultures was adjusted to $1 \times 108 \mathrm{CFU} / \mathrm{mL}$ (equivalent to $0.5 \mathrm{McF}$ arlan standard) using Thermo Spectronic (Model, Helios Epsilon) [Thermo-Fisher Scientific, Waltham, MA, USA]. Aliquot of $100 \mu \mathrm{L}$ of the culture was spread on Muellerf-Hinton agar (Biolab, Lawrenceville, GA, USA). Four carbapenem antibiotic discs: imipenem (IPM, $10 \mu \mathrm{g}$ ), ertapenem (ETP, $10 \mu \mathrm{g}$ ), meropenem (MEM, $10 \mu \mathrm{g}$ and doripenem (DOR, $10 \mu \mathrm{g}$ ) (Mast Diagnostics, Randburg, South Africa) were placed on inoculated plates. The plates were incubated at $37^{\circ} \mathrm{C}$ for $24 \mathrm{~h}$. The results were interpreted using both Clinical Laboratory Standards Institute and European Committee on Antimicrobial Susceptibility Testing guidelines [20,47]. Colonies of all the isolates showing intermediate or resistant phenotypes to one of the three tested antibiotics were further subjected to Modified Hodge Test to confirm their ability to produce carbapenemase [48]. Carbapenemase-negative E. coli (ATCC 25922) and Carbapenemase-positive K. pneumoniae (ATCC BAA-1705) were used as quality control.

\subsection{Phenotypic Screening for Identification of ESBL-Producing Enterobacteriaceae}

The isolates that showed intermediate or resistant phenotypes to at least one of the carbapenem antibiotics were screened for the presence of extended spectrum beta-lactamase (ESBL) traits. Briefly, the isolates were culture on chromogenic Brilliance ${ }^{\mathrm{TM}}$ ESBL agar (Thermo-Fisher Scientific, Waltham, MA, USA). E. coli (ATCC 25922) and K. pneumoniae (ATCC 700603) were used as the quality control organisms. Growth on Brilliance ${ }^{\mathrm{TM}}$ ESBL agar indicated the ability of the isolates to produce extended spectrum beta-lactamase, and the results were interpreted according to manufacturer's instructions.

\subsection{Antimicrobial Susceptibility Test}

All the CRE isolates revealing ESBL characteristics on Brilliance ${ }^{\mathrm{TM}}$ ESBL agar were subjected to antibiotic sensitivity test to determine their antimicrobial resistance profile according to Kirby-Bauer disc diffusion method [46], following Clinical Laboratory Standard Institute guidelines [20]. The thirteen antibiotics used were: Amoxicillin (A, $25 \mu \mathrm{g}$ ), Amoxicillin-clavulanate (AMC, $30 \mu \mathrm{g})$, Aztreonam (ATM, $30 \mu \mathrm{g})$, Cefepime (CPM, $30 \mu \mathrm{g})$, Cefotaxime (CTX, $30 \mu \mathrm{g})$, Cefoxitin (FOX, $30 \mu \mathrm{g})$, Ceftazidime (CAZ, $30 \mu \mathrm{g})$, Cefuroxime (CXM, $30 \mu \mathrm{g})$, Ceftiofur (EFT, $30 \mu \mathrm{g})$, Cephalothin (KF, $30 \mu \mathrm{g})$, Ciprofloxacin (CIP, $5 \mu \mathrm{g}$ ), Piperacillin (PRL, $30 \mu \mathrm{g}$ ) and Ticarcillin (TC, $75 \mu \mathrm{g}$ ) (Mast Diagnostics, Randburg, South Africa). E. coli (ATCC 25922) and K. pneumoniae (ATCC 700603) were used as the quality control organisms. The isolates were classified as sensitive, intermediate resistant or resistant based on standard reference values [20]. Any isolate revealing resistance to at least three or more different antibiotics tested was 
considered multidrug resistant. Multiple antibiotic resistance (MAR) index was determined as the ratio of the number of antibiotics to which CRE isolate showed resistance to the number of antibiotics to which the isolate was exposed [30], using the following formula:

$$
M A R I=X / Y
$$

where ' $X$ ' is the number of antimicrobial agents which bacteria revealed resistance while ' $Y$ ' is the total number of antimicrobial agents tested.

\subsection{DNA Extraction from CRE Isolates}

Genomic DNA was extracted from all CRE/ESBL-producing isolates using the Zymo Research Genomic DNA ${ }^{\mathrm{TM}}$-Tissue MiniPrep Kit (Zymo Research Corp, Irvine, CA, USA) according to the manufacturer's instructions. The quality and quantity of DNA was determined using Nanodrop ${ }^{\text {TM }}$-Lite spectrophotometer (Thermo Scientific, Walton, MA, USA). Pure DNA samples were stored at $-20^{\circ} \mathrm{C}$ for future use.

\subsection{Genus-Specific Identification of CRE Isolates}

Bacterial universal primer was used to amplify bacterial 16S rRNA gene fragments from the genomic DNA. The identities of the isolates were confirmed by genus-specific PCR, targeting the uidA, ntrA, tuf and invA genes specific for E. coli, K. pneumoniae, P. mirabilis and Salmonella species, respectively. Details of oligonucleotide primer sequence and PCR conditions are listed in Table 3. PCR reactions were prepared in standard $25 \mu \mathrm{L}$ (comprising $12.5 \mu \mathrm{L} 2 \times$ DreamTaq Green Master Mix, $0.25 \mu \mathrm{L}$ of each oligonucleotides primer, $11 \mu \mathrm{L}$ RNase-DNase free water and $1 \mu \mathrm{L}$ DNA template). A no DNA template (nuclease-free water) reaction tube served as a negative control while a DNA sample from E. coli (ATCC 25922), K. pneumoniae (ATCC 700603), S. enterica (ATCC 14028 and 12325) were used as quality control organisms. All the PCR reagents were New England Biolabs (Ipswich, MA, USA, supplied by Inqaba, Pretoria, South Africa) products supplied by Inqaba Biotechnical Industry Ltd., Pretoria, South Africa. Amplifications were performed using a DNA thermal cycler (model- Bio-Rad C1000 Touch ${ }^{\mathrm{TM}}$ Thermal Cycler). All PCR products were resolved by agarose gel electrophoresis and the rest were stored at $4{ }^{\circ} \mathrm{C}$.

\subsection{Detection of Carbapenemase-Encoding Genes Using Multiplex PCR}

All confirmed CRE isolates were subjected to Multiplex PCR analysis for detection of carbapenemase resistance genes (blaNDM, blaKPC, blaVIM, blaOXA-23, blaOXA-48 and blaGES). The oligonucleotide primer sequence and PCR conditions are listed in Table 4. PCR reactions were prepared in standard $25 \mu \mathrm{L}$ (comprising of $12.5 \mu \mathrm{L} 2 \times$ DreamTaq Green Master Mix, $0.25 \mu \mathrm{L}$ of each oligonucleotides primer, $11 \mu \mathrm{L}$ RNase-DNase free water and $1 \mu \mathrm{L}$ DNA template). A non-DNA template (nuclease-free water) reaction tube served as a negative control. DNA sample from K. pneumoniae (ATCC BAA-1705), S. enterica (ATCC 14028 and 12325) was used as quality control. All the PCR reagents were New England Biolabs (Ipswitch, MA, USA supplied by Inqaba, Pretoria, South Africa) products supplied by Inqaba Biotechnical Industry Ltd., Pretoria, South Africa. Amplifications were performed using a DNA thermal cycler (model-Bio-Rad C1000 Touch ${ }^{\mathrm{TM}}$ Thermal Cycler). All PCR products were resolved by agarose gel electrophoresis and the rest were stored at $4{ }^{\circ} \mathrm{C}$. 
Table 3. List of oligonucleotide primer sequences and PCR conditions used in this study.

\begin{tabular}{|c|c|c|c|c|c|}
\hline Primers & Oligonucleotide Sequence $\left(5^{\prime}-3^{\prime}\right)$ & Genes & Amplicon Size (bp) & Annealing $\operatorname{Tm}\left({ }^{\circ} \mathrm{C}\right)$ & References \\
\hline \multicolumn{6}{|c|}{ 16S rRNA } \\
\hline $27 \mathrm{~F}$ & AGAGTTTGATCATGGCTCAG & \multirow{2}{*}{$16 \mathrm{~S}$ rRNA } & \multirow{2}{*}{1420} & \multirow{2}{*}{55} & \multirow{2}{*}{ [49] } \\
\hline 1492R & GGTACCTTGTTACGACTT & & & & \\
\hline \multicolumn{6}{|c|}{ Genus Specific Genes } \\
\hline ntrA-F & CATCTCGATCTGCTGGCCAA & \multirow{2}{*}{$n t r A$} & \multirow{2}{*}{90} & \multirow{2}{*}{52} & \multirow{4}{*}[50]{} \\
\hline ntrA-R & GCGCGGATCCAGCGATTGGA & & & & \\
\hline uidA-F & CTGGTATCAGCGCGAAGTC & \multirow{2}{*}{ uidA } & \multirow{2}{*}{556} & \multirow{2}{*}{52} & \\
\hline uidA-R & AGCGGGTAGATATCACACTC & & & & \\
\hline Tuf-F & TCTACTTCACACGTAG & \multirow{2}{*}{ tuf } & \multirow{2}{*}{240} & \multirow{2}{*}{58} & \multirow{2}{*}{ [51] } \\
\hline Tuf-R & TTCTAACAGCTCTTCA & & & & \\
\hline invA-F & GTGAAATTATCGCCACGTGGCAA & \multirow{2}{*}{$\operatorname{inv} A$} & \multirow{2}{*}{284} & \multirow{2}{*}{64} & \multirow{2}{*}{ [52] } \\
\hline invA-R & TCATCGCACCGTCAAAGGAACC & & & & \\
\hline
\end{tabular}


Table 4. List of oligonucleotide primer sequences and PCR conditions used in this study.

\begin{tabular}{|c|c|c|c|c|c|}
\hline Primers & Oligonucleotide Sequence $\left(5^{\prime}-3^{\prime}\right)$ & Genes & Amplicon Size (bp) & Annealing $\operatorname{Tm}\left({ }^{\circ} \mathrm{C}\right)$ & References \\
\hline \multicolumn{6}{|c|}{ CRE Genes } \\
\hline KPC-F & CGTCTAGTTCTGCTGTCTTG & \multirow{2}{*}{$b l a_{\mathrm{KPC}}$} & \multirow{2}{*}{798} & \multirow{12}{*}{52} & \multirow{12}{*}{ [53] } \\
\hline KPC-R & CTTGTCATCCTTGTTAGGCG & & & & \\
\hline NDM-F & GGTTTGGCGATCTGGTTTTC & \multirow{2}{*}{$b l a_{\mathrm{NDM}}$} & \multirow{2}{*}{621} & & \\
\hline NDM-R & CGGAATGGCTCATCACGATC & & & & \\
\hline OXA-23-F & ATGAGTTATCTATTTTTGTC & \multirow{2}{*}{$b l a_{\mathrm{OXA}-23}$} & \multirow{2}{*}{501} & & \\
\hline OXA-23-R & TGTCAAGCTCTTAAATAATA & & & & \\
\hline GES-C-F & GTTTTGCAATGTGCTCAACG & \multirow{2}{*}{$b l a_{\mathrm{GES}}$} & \multirow{2}{*}{371} & & \\
\hline GES-D-R & TGCCATAGCAATAGGCGTAG & & & & \\
\hline VIM-F & GATGGTGTTTGGTCGCATA & \multirow{2}{*}{$b l a_{\mathrm{VIM}}$} & \multirow{2}{*}{390} & & \\
\hline VIM-R & CGAATGCGCAGCACCAG & & & & \\
\hline OXA-48-F & TTCGGCCACGGAGCAAATCAG & \multirow{2}{*}{$b l a_{O X A-48}$} & \multirow{2}{*}{438} & & \\
\hline OXA-48-R & GATGTGGGCATATCCATATTCATCGCA & & & & \\
\hline \multicolumn{6}{|c|}{ ESBL Genes } \\
\hline blaTEM-F & AAACGCTGGTGAAAGTA & \multirow{2}{*}{$b l a_{T E M}$} & \multirow{2}{*}{822} & \multirow{8}{*}{45} & \multirow{8}{*}{ [54] } \\
\hline blaTEM-R & AGCGATCTGTCTAT & & & & \\
\hline blaSHV-F & ATGCGTTATATCGCCTGTG & \multirow{2}{*}{$b l a_{\mathrm{SHV}}$} & \multirow{2}{*}{753} & & \\
\hline blaSHV-R & TGCTTTGTTATTCGGGCCAA & & & & \\
\hline blaCTX-M-F & CGCTTTGCGATGTGCAG & \multirow{2}{*}{$b l a_{\mathrm{CTX}-\mathrm{M}}$} & \multirow{2}{*}{550} & & \\
\hline blaCTX-M-R & ACCGCGATATCGTTGGT & & & & \\
\hline blaOXA-F & ATATCTCTACTGTTGCATCTCC & \multirow{2}{*}{$b l a_{\mathrm{OXA}}$} & \multirow{2}{*}{619} & & \\
\hline blaOXA-R & АААСССТТСАААССАТСС & & & & \\
\hline
\end{tabular}




\subsection{Detection of Extended Spectrum Beta-Lactamase-Encoding Genes in CRE}

The CRE isolates were further screened for the presence of the major ESBL genes (blaCTX-M, blaOXA, blaSHV and blaTEM). Details of oligonucleotide primer sequences and PCR conditions are listed in Table 4. PCR reactions were prepared in standard $25 \mu \mathrm{L}$ (comprising of $12.5 \mu \mathrm{L} 2 \times$ DreamTaq Green Master Mix, $0.25 \mu \mathrm{L}$ of each oligonucleotides primer, $11 \mu \mathrm{L}$ RNase-DNase free water and $1 \mu \mathrm{L}$ DNA template). A no DNA template (nuclease-free water) reaction tube served as a negative control. All the PCR reagents were New England Biolabs (Ipswitch, MA, USA supplied by Inqaba, Pretoria, South Africa) products supplied by Inqaba Biotechnical Industry Ltd., Pretoria, South Africa. Amplifications were performed using a DNA thermal cycler (model: Bio-Rad C1000 Touch ${ }^{\mathrm{TM}} \mathrm{Thermal}^{\mathrm{T}}$ Cycler). All PCR products were resolved by agarose gel electrophoresis and the rest were stored at $4{ }^{\circ} \mathrm{C}$.

\subsection{Agarose Gel Electrophoresis and Visualization}

A $2 \%(w / v)$ agarose gel containing $0.1 \mu \mathrm{g} / \mathrm{mL}$ Ethidium bromide was used to separate all PCR products by electrophoresis. A $1 \mathrm{~Kb}$ or 100 bp DNA molecular weight marker (Fermentas, Foster City, CA, USA) was included in each gel. A horizontal Pharmacia Biotech equipment system (Model Hoefer HE 99X, Amersham Pharmacia Biotech, Stockholm, Sweden) was used to perform the electrophoresis, each cycle ran for $1 \mathrm{~h}$ at $80 \mathrm{~V}$. Visualization and image capturing was performed using a ChemiDoc Imaging System (Bio-Rad ChemiDoc ${ }^{\mathrm{TM}}$ MP Imaging System, Hercules, CA, USA).

\subsection{Statistical Analysis}

The data generated in this study was entered into an Excel spreadsheet. Descriptive analysis was conducted using SAS, 2010 (v 9.4, SAS Institute, Cary, NC, USA). The proportions of positive for E. coli $\mathrm{O} 177$ serotype, antimicrobial resistance and virulence genes across the farms were determined. The analysed data were used to draw tables and bar graphs.

\section{Conclusions}

To the best of our knowledge, this is the first study reporting the occurrence of CR- and ESBL-producing Enterobacteriaceae in South African beef cattle. The results contained herein revealed high MDR phenotypes among CR- and ESBL-producing Enterobacteriaceae. Furthermore, the most frequently detected species were E. coli and K. pneumoniae. Notably, high detection of carbapenemase and/or ESBL resistance determinants in CRE was alarming given the significant importance of carbapenem antibiotics in public health. Therefore, stringent hygiene measures must be enforced to mitigate the spread and transmission of CRE- and ESBL-producing pathogens in beef farms.

Supplementary Materials: The following are available online at http://www.mdpi.com/2079-6382/9/11/820/s1, Table S1: Multidrug resistance phenotypes and MAR index of CRE isolates.

Author Contributions: Conceptualization, C.N.A. and M.M.; methodology, L.T.; software, P.K.M.; validation, L.T., M.C.M. and P.K.M.; formal analysis, L.T.; investigation, L.T.; resources, C.N.A. and M.M.; data curation L.T., M.C.M. and P.K.M.; writing-original draft preparation, L.T., M.C.M. and P.K.M.; writing-review and editing, C.N.A. and M.M.; visualization, L.T., M.C.M. and P.K.M.; supervision, C.N.A. and M.M.; project administration, C.N.A. and M.M.; funding acquisition, C.N.A. and M.M. All authors have read and agreed to the published version of the manuscript.

Funding: This research was funded by HWSETA awarded to L.T. This work was also supported in part by University of Mpumalanga and North West University, South Africa.

Conflicts of Interest: The authors declare no conflict of interest. 


\section{References}

1. Pitout, J.D.D.; Nordmann, P.; Poirel, L. Carbapenemase-Producing Klebsiella pneumoniae, a Key Pathogen Set for Global Nosocomial Dominance. Antimicrob. Agents Chemother. 2015, 59, 5873-5884. [CrossRef] [PubMed]

2. Suay-Garcia, B.; Pérez-Gracia, M.T. Present and Future of Carbapenem-resistant Enterobacteriaceae (CRE) Infections. Antibiotics 2019, 8, 122. [CrossRef] [PubMed]

3. Bartsch, S.; McKinnell, J.; Mueller, L.; Miller, L.; Gohil, S.; Huang, S.; Lee, B.Y. Potential economic burden of carbapenem-resistant Enterobacteriaceae (CRE) in the United States. Clin. Microbiol. Infect. 2017, 23, 48.e9-48.e16. [CrossRef] [PubMed]

4. Antibiotic Resistance Threats in the United States. 2013. Available online: https://www.cdc.gov/ drugresistance/pdf/ar-threats-2013-508.pdf (accessed on 28 September 2020).

5. Ballot, D.E.; Bandini, R.; Nana, T.; Bosman, N.; Thomas, T.; Davies, V.A.; Cooper, P.A.; Mer, M.; Lipman, J. A review of -multidrug-resistant Enterobacteriaceae in a neonatal unit in Johannesburg, South Africa. BMC Pediatr. 2019, 19, 320. [CrossRef]

6. Ramsamy, Y.; Mlisana, K.; Allam, M.; Amoako, D.G.; Abia, A.L.K.; Ismail, A.; Singh, R.; Kisten, T.; Han, K.S.S.; Muckart, D.J.J.; et al. Genomic Analysis of Carbapenemase-Producing Extensively Drug-Resistant Klebsiella pneumoniae Isolates Reveals the Horizontal Spread of p18-43_01 Plasmid Encoding blaNDM-1 in South Africa. Microorganisms 2020, 8, 137. [CrossRef]

7. Boutal, H.; Vogel, A.; Bernabeu, S.; Devilliers, K.; Creton, E.; Cotellon, G.; Plaisance, M.; Oueslati, S.; Dortet, L.; Jousset, A.; et al. A multiplex lateral flow immunoassay for the rapid identification of NDM-, KPC-, IMPand VIM-type and OXA-48-like carbapenemase-producing Enterobacteriaceae. J. Antimicrob. Chemother. 2018, 73, 909-915. [CrossRef]

8. Fernández, J.; Guerra, B.; Rodicio, M.R. Resistance to Carbapenems in Non-Typhoidal Salmonella enterica Serovars from Humans, Animals and Food. Vet. Sci. 2018, 5, 40. [CrossRef]

9. Solgi, H.; Nematzadeh, S.; Giske, C.G.; Badmasti, F.; Westerlund, F.; Lin, Y.-L.; Goyal, G.; Nikbin, V.S.; Nemati, A.H.; Shahcheraghi, F. Molecular Epidemiology of OXA-48 and NDM-1 Producing Enterobacterales Species at a University Hospital in Tehran, Iran, Between 2015 and 2016. Front. Microbiol. 2020, 11, 936. [CrossRef]

10. Teixeira, P.; Tacão, M.; Pureza, L.; Gonçalves, J.; Silva, A.; Cruz-Schneider, M.P.; Henriques, I. Occurrence of carbapenemase-producing Enterobacteriaceae in a Portuguese river: blaNDM, blaKPC and blaGES among the detected genes. Environ. Pollut. 2020, 260, 113913. [CrossRef]

11. Li, M.; Guo, M.; Chen, L.; Zhu, C.; Xiao, Y.; Li, P.; Guo, H.; Chen, L.; Zhang, W.; Du, H. Isolation and Characterization of Novel Lytic Bacteriophages Infecting Epidemic Carbapenem-Resistant Klebsiella pneumoniae Strains. Front. Microbiol. 2020, 11, 1554. [CrossRef]

12. Shrivastava, S.R.; Shrivastava, P.S.; Ramasamy, J. World health organization releases global priority list of antibiotic-resistant bacteria to guide research, discovery, and development of new antibiotics. J. Med Soc. 2018, 32, 76. [CrossRef]

13. Zhen, X.; Lundborg, C.S.; Sun, X.; Hu, X.; Dong, H. Economic burden of antibiotic resistance in ESKAPE organisms: A systematic review. Antimicrob. Resist. Infect. Control. 2019, 8, 1-23. [CrossRef] [PubMed]

14. Han, R.; Shi, Q.; Wu, S.; Yin, D.; Peng, M.; Dong, D.; Zheng, Y.; Guo, Y.; Zhang, R.; Hu, F.; et al. Dissemination of Carbapenemases (KPC, NDM, OXA-48, IMP, and VIM) Among Carbapenem-Resistant Enterobacteriaceae Isolated From Adult and Children Patients in China. Front. Cell. Infect. Microbiol. 2020, 10, 314. [CrossRef] [PubMed]

15. Gazin, M.; Paasch, F.; Goossens, H.; Malhotra-Kumar, S. Current Trends in Culture-Based and Molecular Detection of Extended-Spectrum- -Lactamase-Harboring and Carbapenem-Resistant Enterobacteriaceae. J. Clin. Microbiol. 2012, 50, 1140-1146. [CrossRef]

16. Ben Said, L.; Jouini, A.; Klibi, N.; Dziri, R.; Alonso, C.A.; Boudabous, A.; Ben Slama, K.; Torres, C. Detection of extended-spectrum beta-lactamase (ESBL)-producing Enterobacteriaceae in vegetables, soil and water of the farm environment in Tunisia. Int. J. Food Microbiol. 2015, 203, 86-92. [CrossRef] 
17. Köck, R.; Daniels-Haardt, I.; Becker, K.; Mellmann, A.; Friedrich, A.W.; Mevius, D.; Schwarz, S.; Jurke, A. Carbapenem-resistant Enterobacteriaceae in wildlife, food-producing, and companion animals: A systematic review. Clin. Microbiol. Infect. 2018, 24, 1241-1250. [CrossRef]

18. Zhang, W.; Zhu, Y.; Wang, C.; Liu, W.; Li, R.; Chen, F.; Luan, T.; Zhang, Y.; Schwarz, S.; Liu, S. Characterization of a Multidrug-Resistant Porcine Klebsiella pneumoniae Sequence Type 11 Strain Coharboring blaKPC-2 and fosA3 on Two Novel Hybrid Plasmids. mSphere 2019, 4, 00590-19. [CrossRef]

19. Gondal, A.J.; Saleem, S.; Jahan, S.; Choudhry, N.; Yasmin, N. Novel Carbapenem-Resistant Klebsiella pneumoniae ST147 Coharboring blaNDM-1, blaOXA-48 and Extended-Spectrum $\beta$-Lactamases from Pakistan. Infect. Drug Resist. 2020, 13, 2105-2115. [CrossRef]

20. CLSI. Performance Standards for Antimicrobial Susceptibility Testing, 28th ed.; Supplement M100; Clinical and Laboratory Standards Institute: Wayne, PA, USA, 2018.

21. Kanj, S.S.; Kanafani, Z.A. Current Concepts in Antimicrobial Therapy Against Resistant Gram-Negative Organisms: Extended-Spectrum $\beta$-Lactamase-Producing Enterobacteriaceae, Carbapenem-Resistant Enterobacteriaceae, and Multidrug-Resistant Pseudomonas aeruginosa. Mayo Clin. Proc 2011, 86, 250-259. [CrossRef]

22. Potter, R.F.; D'Souza, A.W.; Dantas, G. The rapid spread of carbapenem-resistant Enterobacteriaceae. Drug Resist. Updates 2016, 29, 30-46. [CrossRef]

23. Mills, M.C.; Lee, J. The threat of carbapenem-resistant bacteria in the environment: Evidence of widespread contamination of reservoirs at a global scale. Environ. Pollut. 2019, 255, 113143. [CrossRef] [PubMed]

24. Ateba, C.N.; Bezuidenhout, C. Characterisation of Escherichia coli O157 strains from humans, cattle and pigs in the North-West Province, South Africa. Int. J. Food Microbiol. 2008, 128, 181-188. [CrossRef] [PubMed]

25. Dlamini, B.S.; Montso, P.K.; Kumar, A.; Ateba, C.N. Distribution of virulence factors, determinants of antibiotic resistance and molecular fingerprinting of Salmonella species isolated from cattle and beef samples: Suggestive evidence of animal-to-meat contamination. Environ. Sci. Pollut. Res. 2018, 25, 32694-32708. [CrossRef] [PubMed]

26. Montso, K.P.; Dlamini, S.B.; Kumar, A.; Ateba, C.N. Antimicrobial Resistance Factors of Extended-Spectrum Beta-Lactamases Producing Escherichia coli and Klebsiella pneumoniae Isolated from Cattle Farms and Raw Beef in North-West Province, South Africa. BioMed Res. Int. 2019, 2019, 1-13. [CrossRef] [PubMed]

27. Richter, L.; Du Plessis, E.M.; Duvenage, S.; Korsten, L. Occurrence, Identification, and Antimicrobial Resistance Profiles of Extended-Spectrum and AmpC $\beta$-Lactamase-Producing Enterobacteriaceae from Fresh Vegetables Retailed in Gauteng Province, South Africa. Foodborne Pathog. Dis. 2019, 16, 421-427. [CrossRef]

28. Magiorakos, A.-P.; Srinivasan, A.; Carey, R.; Carmeli, Y.; Falagas, M.; Giske, C.; Harbarth, S.J.; Hindler, J.; Kahlmeter, G.; Olsson-Liljequist, B.; et al. Multidrug-resistant, extensively drug-resistant and pandrug-resistant bacteria: An international expert proposal for interim standard definitions for acquired resistance. Clin. Microbiol. Infect. 2012, 18, 268-281. [CrossRef]

29. Fadare, F.T.; Adefisoye, M.A.; Okoh, A.I. Occurrence, identification and antibiogram signatures of selected Enterobacteriaceae from Tsomo and Tyhume rivers in the Eastern Cape Province, Republic of South Africa. bioRxiv 2020, 2-46. [CrossRef]

30. Krumperman, P.H. Multiple antibiotic resistance indexing of Escherichia coli to identify high-risk sources of faecal contamination of foods. Appl. Environ. Microbiol. 1983, 46, 165-170. [CrossRef]

31. Ahmed, H.A.; El Bayomi, R.M.; Hussein, M.A.; Khedr, M.H.; Remela, E.M.A.; El-Ashram, A.M. Molecular characterization, antibiotic resistance pattern and biofilm formation of Vibrio parahaemolyticus and V. cholerae isolated from crustaceans and humans. Int. J. Food Microbiol. 2018, 274, 31-37. [CrossRef]

32. Sheu, C.-C.; Chang, Y.-T.; Lin, S.-Y.; Chen, Y.-H.; Hsueh, P.-R. Infections Caused by Carbapenem-Resistant Enterobacteriaceae: An Update on Therapeutic Options. Front. Microbiol. 2019, 10, 80. [CrossRef]

33. Liu, B.-T.; Zhang, X.-Y.; Wan, S.-W.; Hao, J.-J.; Jiang, R.-D.; Song, F.-J. Characteristics of Carbapenem-Resistant Enterobacteriaceae in Ready-to-Eat Vegetables in China. Front. Microbiol. 2018, 9, 1147. [CrossRef]

34. Perovic, O.; Germs-Sa, F.; Ismail, H.; Quan, V.; Bamford, C.; Nana, T.; Chibabhai, V.; Bhola, P.; Ramjathan, P.; Swe-Han, K.S.; et al. Carbapenem-resistant Enterobacteriaceae in patients with bacteraemia at tertiary hospitals in South Africa, 2015 to 2018. Eur. J. Clin. Microbiol. Infect. Dis. 2020, 39, 1287-1294. [CrossRef] 
35. Grundmann, H.; Glasner, C.; Albiger, B.; Aanensen, D.M.; Tomlinson, C.T.; Andrasević, A.T.; Cantón, R.; Carmeli, Y.; Friedrich, A.W.; Giske, C.G.; et al. Occurrence of carbapenemase-producing Klebsiella pneumoniae and Escherichia coli in the European survey of carbapenemase-producing Enterobacteriaceae (EuSCAPE): A prospective, multinational study. Lancet Infect. Dis. 2017, 17, 153-163. [CrossRef]

36. Bleichenbacher, S.; Stevens, M.J.; Zurfluh, K.; Perreten, V.; Endimiani, A.; Stephan, R.; Nüesch-Inderbinen, M. Environmental dissemination of carbapenemase-producing Enterobacteriaceae in rivers in Switzerland. Environ. Pollut. 2020, 265, 115081. [CrossRef] [PubMed]

37. Braun, S.D.; Ahmed, M.F.E.; El-Adawy, H.; Hotzel, H.; Engelmann, I.; Weiß, D.; Monecke, S.; Ehricht, R. Surveillance of Extended-Spectrum Beta-Lactamase-Producing Escherichia coli in Dairy Cattle Farms in the Nile Delta, Egypt. Front. Microbiol. 2016, 7, 1020. [CrossRef] [PubMed]

38. Bradford, P.A. Extended-Spectrum $\beta$-Lactamases in the 21st Century: Characterization, Epidemiology, and Detection of This Important Resistance Threat. Clin. Microbiol. Rev. 2001, 14, 933-951. [CrossRef] [PubMed]

39. Peirano, G.; Pitout, J.D. Extended-Spectrum $\beta$-Lactamase-Producing Enterobacteriaceae: Update on Molecular Epidemiology and Treatment Options. Drugs 2019, 79, 1529-1541. [CrossRef]

40. Ahmed, A.M.; Shimamoto, T. Molecular analysis of multidrug resistance in Shiga toxin-producing Escherichia coli O157:H7 isolated from meat and dairy products. Int. J. Food Microbiol. 2015, 193, 68-73. [CrossRef]

41. Das, L.; Borah, P.; Sharma, R.; Malakar, D.; Saikia, G.K.; Tamuly, S.; Dutta, R.; Sharma, K. Phenotypic and molecular characterization of extended spectrum $\beta$-lactamase producing Escherichia coli and Klebsiella pneumoniae isolates from various samples of animal origin from Assam, India. bioRxiv 2020, 1-22. [CrossRef]

42. Geser, N.; Stephan, R.; Hächler, H. Occurrence and characteristics of extended-spectrum $\beta$-lactamase (ESBL) producing Enterobacteriaceae in food producing animals, minced meat and raw milk. BMC Vet. Res. 2012, 8, 21. [CrossRef]

43. Adator, E.H.; Narvaez-Bravo, C.; Zaheer, R.; Cook, S.R.; Tymensen, L.; Hannon, S.J.; Booker, C.W.; Church, D.L.; Read, R.R.; McAllister, T.A. A One Health Comparative Assessment of Antimicrobial Resistance in Generic and Extended-Spectrum Cephalosporin-Resistant Escherichia coli from Beef Production, Sewage and Clinical Settings. Microorganisms 2020, 8, 885. [CrossRef] [PubMed]

44. Vasaikar, S.D.; Obi, L.; Morobe, I.; Bisi-Johnson, M. Molecular Characteristics and Antibiotic Resistance Profiles ofKlebsiellaIsolates in Mthatha, Eastern Cape Province, South Africa. Int. J. Microbiol. 2017, 2017, 1-7. [CrossRef] [PubMed]

45. Richter, L.; Du Plessis, E.M.; Duvenage, S.; Korsten, L. Occurrence, Phenotypic and Molecular Characterization of Extended-Spectrum- and AmpC- $\beta$-Lactamase Producing Enterobacteriaceae Isolated From Selected Commercial Spinach Supply Chains in South Africa. Front. Microbiol. 2020, 11, 638. [CrossRef] [PubMed]

46. Bauer, M.A.W.; Kirby, M.W.M.M.; Sherris, M.J.C.; Turck, M.M. Antibiotic Susceptibility Testing by a Standardized Single Disk Method. Am. J. Clin. Pathol. 1966, 45, 493-496. [CrossRef]

47. EUCAST Guidelines for Detection of Resistance Mechanisms and Specific Resistance of Clinical and/or Epidemiological Importance. Available online: https://eucast.org/resistance_mechanisms/ (accessed on 13 November 2020).

48. Amjad, A.; Mirza, I.; Abbasi, S.; Farwa, U.; Malik, N.; Zia, F. Modified Hodge test: A simple and effective test for detection of carbapenemase production. Iran. J. Microbiol. 2011, 3, 189-193.

49. Korzeniewska, E.; Harnisz, M. Beta-lactamase-producing Enterobacteriaceae in hospital effluents. J. Environ. Manag. 2013, 123, 1-7. [CrossRef]

50. Anbazhagan, D.; Mui, W.S.; Mansor, M.; Yan, G.O.S.; Yusof, M.Y.; Sekaran, S.D. Development of conventional and real-time multiplex PCR assays for the detection of nosocomial pathogens. Braz. J. Microbiol. 2011, 42, 448-458. [CrossRef]

51. Anbazhagan, D.; Kathirvalu, G.G.; Mansor, M.; Yan, G.O.S.; Yusof, M.Y.; Sekaran, S.D. Multiplex polymerase chain reaction (PCR) assays for the detection of Enterobacteriaceae in clinical samples. Afr. J. Microbiol. Res. 2010, 4, 1186-1191.

52. Salehi, T.Z.; Mahzounieh, M.; Saeedzadeh, A. Detection of InvA Gene in Isolated Salmonella from Broilers by PCR Method. Int. J. Poult. Sci. 2005, 4, 557-559. [CrossRef] 
53. Poirel, L.; Walsh, T.R.; Cuvillier, V.; Nordmann, P. Multiplex PCR for detection of acquired carbapenemase genes. Diagn. Microbiol. Infect. Dis. 2011, 70, 119-123. [CrossRef]

54. Al-Mayahie, S.M.G. Phenotypic and genotypic comparison of ESBL production by Vaginal Escherichia coli isolates from pregnant and non-pregnant women. Ann. Clin. Microbiol. Antimicrob. 2013, 12, 1-7. [CrossRef] [PubMed]

Publisher's Note: MDPI stays neutral with regard to jurisdictional claims in published maps and institutional affiliations.

(C) 2020 by the authors. Licensee MDPI, Basel, Switzerland. This article is an open access article distributed under the terms and conditions of the Creative Commons Attribution (CC BY) license (http://creativecommons.org/licenses/by/4.0/). 